OPEN ACCESS

Edited by:

Gordon Li,

Stanford University,

United States

Reviewed by:

Brigitta G. Baumert,

Maastricht University Medical

Centre, Netherlands

Jonathon Parkinson,

University of Sydney, Australia

*Correspondence:

Ibrahim Sun

halilibrahim.sun@acibadem.edu.tr

Specialty section: This article was submitted to Neuro-Oncology and Neurosurgical Oncology, a section of the journal Frontiers in Neurology

Received: 28 March 2017 Accepted: 19 June 2017 Published: 17 July 2017

Citation:

Sun I and Pamir MN (2017) Non-Syndromic Spinal Schwannomas: A Novel Classification.

Front. Neurol. 8:318. doi: 10.3389/fneur.2017.00318

\section{Non-Syndromic Spinal Schwannomas: A Novel Classification}

\author{
Ibrahim Sun* and M. Necmettin Pamir \\ Department of Neurosurgery, Acıbadem University School of Medicine, Istanbul, Turkey
}

Schwannomas are the most frequent primary tumors of the spine with an incidence of 0.3-0.5/100,000 person per year. Current treatment for non-syndromic spinal schwannomas is total resection of the tumor with preservation of neurovascular structures. This study aims to report neurologic and radiologic outcome following treatment of nonsyndromic spinal schwannomas along with a novel tumor classification used in our clinic. A retrospective case series was carried out with a patient sample of 82 male and female patients with non-syndromic spinal schwannomas. All patient data were retrospectively collected from the hospital records. As a routine procedure, after admittance and primary evaluation, patients' tumors were classified using CT or MRI in accordance with our proposed classification method, which employs a dual designation method with tree groups (A, B, and C) for tumor volume and four types (I, II, III, and IV) for tumor localization. Subsequent resection surgery was followed by neurological assessments and follow up at 45th, 180th, and 360th postoperative day. Along with Karnofsky performance status scale, pain, sensory deficits, and motor weakness were scored to assess neurologic recovery. Our finding indicates that patients with different tumor types significantly differ in their neurological scores and show consistent but differential neurological recovery at early and late time points postsurgery. Complications during and postsurgery were minimal, occurring only in two patients. Our findings further reinforce the established safety of total resection operations and indicate that our proposed classification is a simple, effective tool that has proven helpful in preoperative planning and avoiding unnecessary surgical approaches.

Keywords: spinal schwannoma, resection surgery, tumor classification, postoperative recovery, spinal tumor

\section{INTRODUCTION}

Schwannoma is the most common nerve sheat tumor. The incidence of spinal schwannoma is $0.3-0.5 / 100,000$ individuals annually (1). Its prevalence is similar in males and females, and it is usually diagnosed during the fourth and fifth decades of life (2). Schwannomas commonly occur in the lumbar and cervical regions and originate from Schwann cell progenitors (3). Schwannomas are benign tumors that are typically round, well demarcated, and encapsulated. Multiple schwannomas in a patient are referred to as schwannomatosis. Schwannomatosis is usually indicative of an underlying tumor predisposition syndrome, such as neurofibromatosis (4). Among schwannoma patients, $3-4 \%$ has multiple tumors (schwannomatosis) (5). Earlier findings suggest that schwannomatosis is a disease that is distinct from non-syndromic schwannomas, both genetically and clinically (6) and, therefore, should be treated accordingly. 
Patients with non-syndromic spinal schwannoma usually present to hospital with local pain and neurological deficit that exacerbate over time. Currently, the standard treatment is gross total resection (GTR) of the tumor with as much preservation of neurovascular structures as possible (7). In 1888, Victor Horsley successfully removed an intraspinal tumor (located at the sixth and seventh thoracic vertebra) for the first time (8). In the midst of such advances, preoperative planning remains crucial for successful treatment and relies-to a great extent-on proper tumor classification. The literature includes multiple classification systems for spinal schwannomas, each of which is associated with both positive and negative ramifications for preoperative planning (9-12). Consequently, there is a lack of consensus concerning the optimal system of classification for schwannomas.

The present study aimed to report on the utility of the novel schwannoma classification system used by our neurosurgery department, based on a 27-year review of non-syndromic spinal schwannoma cases that were surgically treated. A review of the literature is also included to provide a detailed overview and comparison of the success rates for other current treatment methods and classification systems.

\section{MATERIALS AND METHODS}

\section{Patients}

The study included 82 patients that were surgically treated between 1987 and 2015. All patient data were retrospectively obtained from the hospital records and were classified with respect to clinical presentation, radiologic features, and surgical outcomes tumor classification was performed based on CT findings. CT and myelography were used to diagnose schwannomas until 1990; thereafter, diagnosis was performed using MRI. MRI images were not available for three patients, and their tumors were classified based on CT findings.

\section{Classification}

Tumors were classified according to our novel classification system, which is based on consideration of tumor volume and localization relative to the dura and spinal canal. For approximate calculation of tumor volume, spinal schwannomas were considered ellipsoid bodies, and tumor volume was calculated using the following formula:

$$
\begin{aligned}
\text { tumor volume }= & 4 / 3 \pi \times(\text { craniocaudal length } / 2) \\
& \times(\text { transverse diameter } / 2)^{2} .
\end{aligned}
$$

Tumors were then assigned to 1-3 volume groups (group A, B, and C) and designated as 1 of 4 types (type I, II, III, and IV) according to localization (i.e., group B type II tumor). Tumor volume $<2 \mathrm{~cm}^{3}$ was considered group A, $2-4 \mathrm{~cm}^{3}$ group $\mathrm{B}$, and $>4 \mathrm{~cm}^{3}$ group C. Tumor typing was as follows: localized exclusively intradurally: type I; intradural localization with extradural extension to the nerve root foramina, but restricted to the spinal canal: type II; intradural dumbbell-shaped tumor in the spinal canal extending to the extraforaminal region: type III; and localized completely outside the root foramina: type IV (Figure 1).

\section{Surgery}

All tumors were removed via a posterior approach. Laminectomy was performed over the appropriate number of levels; where necessary this was expanded to include the medial facet. Ultrasonic aspiration was used to facilitate tumor debulking. The aim of the surgery was to remove the tumor while preserving the parent nerve. For type III tumors, intracapsular resection was performed via CUSA, followed by dissection performed from the intradural to extradural side. Bone removal is not necessary in cases of type IV tumors, and in such cases direct tumor exposure was performed. The aim of all surgeries was GTR and preservation of the parent nerve. Tumor resection was performed microsurgically, and an ultrasonic aspirator was used for enucleation. Among


FIGURE 1 | Schwannomas types (according to the present study's novel classification system) as seen in the coronal and transverse planes. 
the patients included in the study, intraoperative monitorization with somatosensorial-evoked potentials was used in 57 (70\%) that underwent surgery after 2000 .

\section{Follow-up}

Gross total resection was confirmed in 79 patients based on MRI performed $24 \mathrm{~h}$ post surgery. Follow-up was performed using CT in three patients prior to 1990, as MRI was not available at that time. Follow-up examinations were performed 45 days, 3 months, and 1 year post surgery, and then yearly for the next 4 years (total: 5 years), but follow-up results for the first postsurgery year only are included in the study. For statistical analysis, each patient's clinical course was scored via the Klekamp and Samii (13) scoring system, which was designed for all types of spinal schwannomas considered by the novel classification system used in the present study. Pain, sensory deficit, motor weakness, and Karnofsky scores were recorded in each patient before surgery, $24 \mathrm{~h}$ post surgery, and 45 days, 3 months, and 1 year post surgery (Table 2).

\section{Statistical Analysis}

Patient results were summarized with mean, SD; whereas categorical variables were summarized with count and percentage. Preoperative, postoperative 45th day, 3rd month, and 1st year results were compared among different types (according to our classification) of spinal schwannomas. One-way between-subject ANOVA was run since the design aimed to analyze the mean differences between the types of tumors according to our classificatory system, $k=4$.

\section{Ethical Consideration}

The study protocol was approved by the Acrbadem University Ethics Committee, Istanbul, Turkey. All patients provided written informed consent for use of their data in this study.

\section{RESULTS}

The study included 82 patients with non-syndromic spinal schwannoma. Cystic components were noted in 10 of the patients.

TABLE 1 | Frequencies for tumor size and location of patients according to our proposed classification.

\begin{tabular}{|c|c|c|c|c|c|}
\hline & & $\begin{array}{c}\text { Cervical, } \\
n(\%)\end{array}$ & $\begin{array}{c}\text { Thoracic, } \\
n(\%)\end{array}$ & $\begin{array}{c}\text { Lumbar, } \\
n(\%)\end{array}$ & Total \\
\hline \multirow[t]{3}{*}{ Type I } & A & 3 (3.6\%) & $4(4.9 \%)$ & 12 (14.9\%) & $19(23.1 \%)$ \\
\hline & $B$ & $2(2.4 \%)$ & 8 (9.9\%) & $6(7.3 \%)$ & 16 (19.5\%) \\
\hline & C & $3(3.6 \%)$ & $4(4.9 \%)$ & - & 7 (8.5\%) \\
\hline \multirow[t]{3}{*}{ Type II } & $A$ & 4 (4.9\%) & - & $2(2.4 \%)$ & $6(7.3 \%)$ \\
\hline & B & $6(7.3 \%)$ & $1(1.2 \%)$ & 3 (3.6\%) & $10(12.2 \%)$ \\
\hline & C & $6(7.3 \%)$ & - & $2(2.4 \%)$ & 8 (9.9\%) \\
\hline \multirow[t]{3}{*}{ Type III } & $A$ & - & - & - & - \\
\hline & $B$ & $4(4.9 \%)$ & - & - & $4(4.9 \%)$ \\
\hline & C & $5(6.1 \%)$ & - & $1(1.2 \%)$ & $6(7.3 \%)$ \\
\hline \multirow[t]{3}{*}{ Type IV } & A & - & - & - & - \\
\hline & B & $1(1.2 \%)$ & - & $5(6.1 \%)$ & $6(7.3 \%)$ \\
\hline & C & - & - & - & - \\
\hline Total & & 34 (41.4\%) & 17 (20.9\%) & 31 (37.3\%) & 82 (100\%) \\
\hline
\end{tabular}

The surgical procedure was the same in patients with and without tumors with cystic components. The patient population consisted of $39(47.5 \%)$ females and $43(52.5 \%)$ males, with a mean age of 45.4 years (range: 18-77 years). In all, almost half of the patients' spinal schwannomas were group B (volume of $2-4 \mathrm{~cm}^{3}$ ). Based on MRI, schwannomas are well-circumscribed, appear isointense to hypointense in T1-weighted images and primarily hyperintense in T2-weighted images, and exhibit various patterns of contrast enhancement. GTR was achieved in 81 patients versus incomplete resection in 1 patient in which vertebral artery injury occurred during resection of the anterior portion of the tumor. Schwannoma localization was cervical in 34 (43\%) patients, thoracic in $17(21 \%)$, and lumbar in $31(36 \%)$. According to our novel classification system, based on tumor volume the tumors were categorized as group A in $25(30 \%)$ patients, versus group B in $36(44 \%)$ and group C in $21(26 \%)$ (Table 1). The most common schwannoma type was type I $[n=42(51 \%)]$ (Figures 2 and 3), followed by type II [ $n=24(29 \%)]$ (Figure 4), type III $[n=10(12 \%)]$ (Figure 5), and type IV $[n=6(8 \%)]$ (Figures 6 and 7). Symptoms at presentation were pain in 65 patients (79\%), paresthesia and/or numbness in 43 (52\%), and motor weakness in $21(26 \%)$ (Table 2$)$. In all, two patients had postoperative lumbar drainage, which did not cause infection.

Preoperative pain, sensory deficit, and motor weakness scores differed significantly according to schwannoma type $(P<0.001$ in all tumor groups). The Karnofsky score were improved in all the patients at all postsurgery time points $(P>0.05)$, but only significantly at 1 year post surgery $(P<0.017)$ (Table 2$)$. Only

TABLE 2 | Patients' neurological scores of with different tumor types at preoperative, postoperative, and follow-up time points.

\begin{tabular}{lccccc}
\hline \multicolumn{1}{c}{$\begin{array}{c}\text { Type I } \\
(\boldsymbol{n}=\mathbf{4 2})\end{array}$} & $\begin{array}{c}\text { Type II } \\
(\boldsymbol{n}=\mathbf{2 4})\end{array}$ & $\begin{array}{c}\text { Type III } \\
(\boldsymbol{n}=\mathbf{1 0})\end{array}$ & $\begin{array}{c}\text { Type IV } \\
(\boldsymbol{n}=\mathbf{6})\end{array}$ & $\boldsymbol{P}$ \\
\hline Pain & & & & & \\
Preoperative & $2.8 \pm 0.2$ & $3.4 \pm 0.4$ & $3.6 \pm 0.6$ & $4.0 \pm 0.7$ & $<0.001$ \\
24 h & $3.0 \pm 0.2$ & $4.1 \pm 0.3$ & $4.8 \pm 0.3$ & $4.2 \pm 0.8$ & $<0.001$ \\
45 days & $3.5 \pm 0.2$ & $4.2 \pm 0.2$ & $4.1 \pm 0.4$ & $4.5 \pm 0.6$ & $<0.001$ \\
3 months & $3.7 \pm 0.2$ & $4.2 \pm 0.3$ & $4.2 \pm 0.5$ & $4.7 \pm 0.5$ & $<0.001$ \\
1 year & $3.6 \pm 0.2$ & $4.4 \pm 0.2$ & $4.5 \pm 0.4$ & $4.7 \pm 0.5$ & $<0.001$ \\
Sensory deficit & & & & & \\
Preoperative & $3.7 \pm 0.2$ & $2.4 \pm 0.3$ & $2.8 \pm 0.6$ & $3.3 \pm 0.9$ & $<0.001$ \\
24 h & $3.9 \pm 0.2$ & $3.5 \pm 0.3$ & $3.5 \pm 0.5$ & $3.5 \pm 0.9$ & 0.121 \\
45 days & $4.0 \pm 0.2$ & $3.7 \pm 0.2$ & $3.6 \pm 0.5$ & $3.8 \pm 0.8$ & 0.277 \\
3 months & $4.1 \pm 0.2$ & $4.2 \pm 0.2$ & $4.0 \pm 0.3$ & $4.0 \pm 0.7$ & 0.752 \\
1 year & $4.2 \pm 0.2$ & $4.2 \pm 0.2$ & $4.2 \pm 0.5$ & $4.0 \pm 0.7$ & 0.922 \\
Motor weakness & & & & & \\
Preoperative & $3.1 \pm 0.2$ & $4.0 \pm 0.3$ & $3.3 \pm 0.6$ & $4.2 \pm 0.8$ & $<0.001$ \\
24 h & $4.2 \pm 0.2$ & $3.1 \pm 0.3$ & $3.4 \pm 0.6$ & $4.2 \pm 0.8$ & $<0.001$ \\
45 days & $4.3 \pm 0.2$ & $4.1 \pm 0.2$ & $3.8 \pm 0.6$ & $4.7 \pm 0.5$ & 0.043 \\
3 months & $4.2 \pm 0.2$ & $4.2 \pm 0.2$ & $3.9 \pm 0.5$ & $4.7 \pm 0.5$ & 0.141 \\
1 year & $4.7 \pm 0.1$ & $4.4 \pm 0.2$ & $3.5 \pm 0.5$ & $4.7 \pm 0.5$ & $<0.001$ \\
Karnofsky score & $74.3 \pm 2.9$ & $72.1 \pm 3.1$ & $73.0 \pm 3.5$ & $70.0 \pm 6.6$ & 0.538 \\
Preoperative & $77.9 \pm 2.3$ & $76.7 \pm 2.4$ & $78.0 \pm 4.5$ & $76.7 \pm 5.4$ & 0.890 \\
24 h & $79.8 \pm 2.1$ & $80.0 \pm 2.8$ & $81.0 \pm 6.3$ & $83.3 \pm 5.4$ & 0.671 \\
45 days & $88.1 \pm 2.2$ & $84.6 \pm 3.1$ & $84.0 \pm 5.0$ & $86.7 \pm 5.4$ & 0.163 \\
3 months & $89.8 \pm 2.2$ & $87.9 \pm 2.8$ & $82.0 \pm 2.8$ & $88.3 \pm 7.9$ & 0.017 \\
1 year & & & & & \\
\hline
\end{tabular}

$95 \%$ confidence intervals and $P$ value for non-significant results for $P=0.05$ are presented. One-way between-subjects ANOVA is used. 

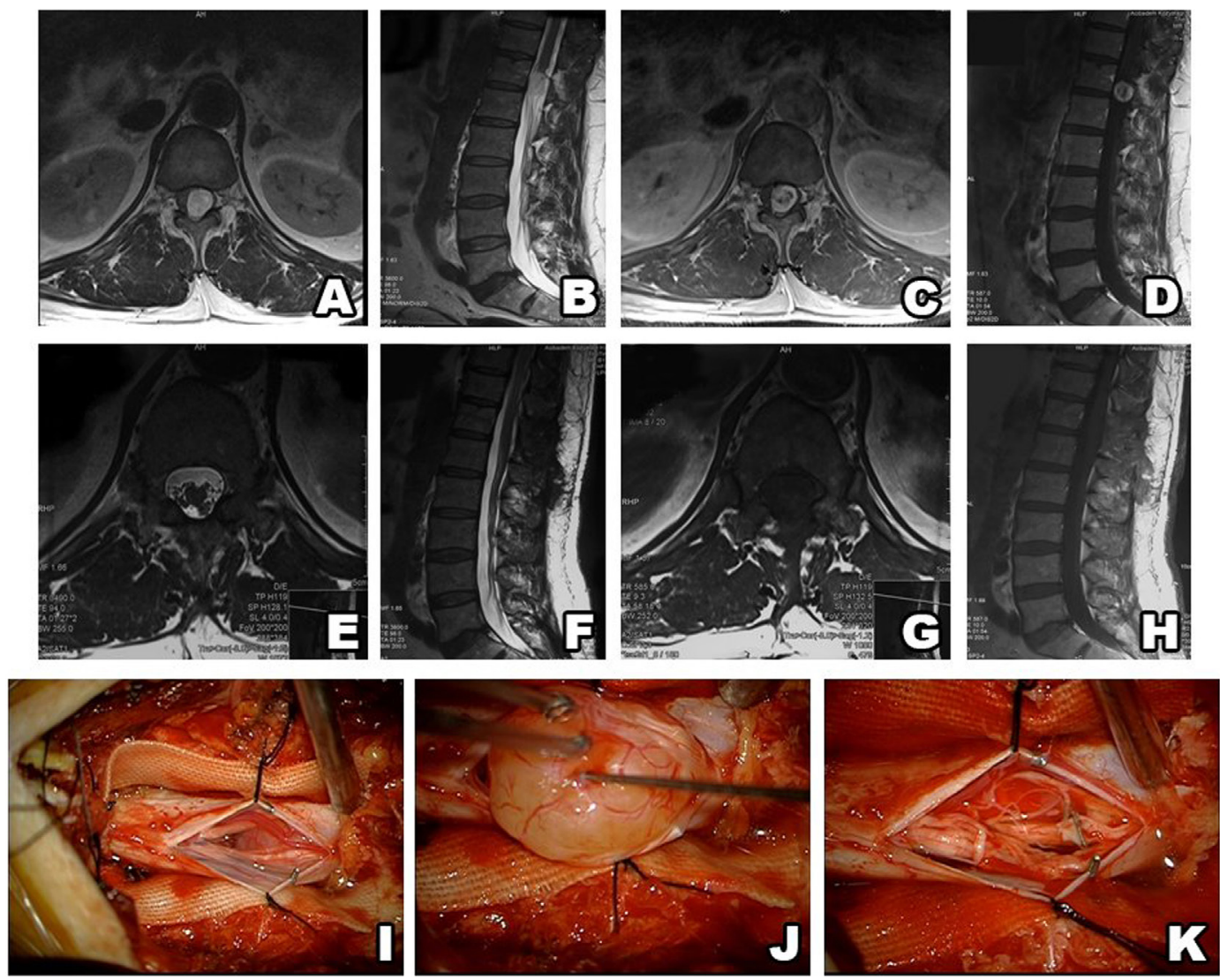

FIGURE 2 | Type I schwannoma (intradural localization). MRI shows a heterogeneous, contrast-enhanced intradural tumor (A-D). Postsurgery MRI confirms gross total resection, without hematoma or recurrence (E-H). Intraoperative photos before and after tumor resection (I-K).

one patient developed postoperative wound infection and was treated with antibiotics. Another two patients had a CSF fistula that was treated with lumbar drainage, after which time they were removed without any complication. In all, two patients showed signs of clinical deterioration after surgery, but both recovered within 2 weeks. At 1 year post surgery all the patients were alive.

\section{DISCUSSION}

Spinal schwannomas account for approximately $25 \%$ of all spinal tumors and are the most common nerve sheath tumors $(3,11)$. Mitotic figures are rarely observed in schwannomas (14). Similar to earlier reports, in the present study cervical and lumbar schwannoma localization was more common than thoracic (1). MRI facilitates easy differentiation of extradural, intraduralextramedullary, and intramedullary schwannomas (15) and is routinely used to examine spinal schwannomas by our department. Preoperative management and postoperative monitorization for schwannoma recurrence are performed using MRI in our department.

Depending on localization, patients with spinal schwannomas primarily present with radicular pain and radiculopathy. Numbness, paresthesia, and motor weakness may also be present, but in the present study the initial symptom was pain in $65(79 \%)$ of the patients. In the present study, pain, sensory deficit, motor weakness, and Karnofsky scores did not improve in those with type I and type IV tumors. In patients with type II and type III tumors, improvement was observed after surgery, but it was not significant. Spinal schwannomas primarily originate from the sensorial division of the nerves, and these data support why the sensory deficit score did not improve significantly for all types of tumors. As compared to presurgery, the Karnofsky score $24 \mathrm{~h}$ post surgery did not improve significantly for any type of schwannoma; however, at 1 year post surgery, it improved significantly for every type.

Whether or not to perform GTR and sacrifice the functionally important root remains a critical decision for surgeons. Kim et al. (12) reported 31 cases that involved the functionally important root (C5-T1 or L3-S1) in which GTR was achieved by sacrificing the root. They reported a neurologic deficit rate of $23 \%$, but that the observed deficit was not functionally debilitating in any of the cases. In the present study, none of the patients had additional nerve deficit after scarifying the nerves affected by schwannoma.

Sarcomatous degeneration has been reported in patients with neurofibromatosis (15). Molecular and genetic studies show that schwannomatosis is a distinct genetic and clinic syndrome (16); therefore, schwannomatosis patients with neurofibromatosis 

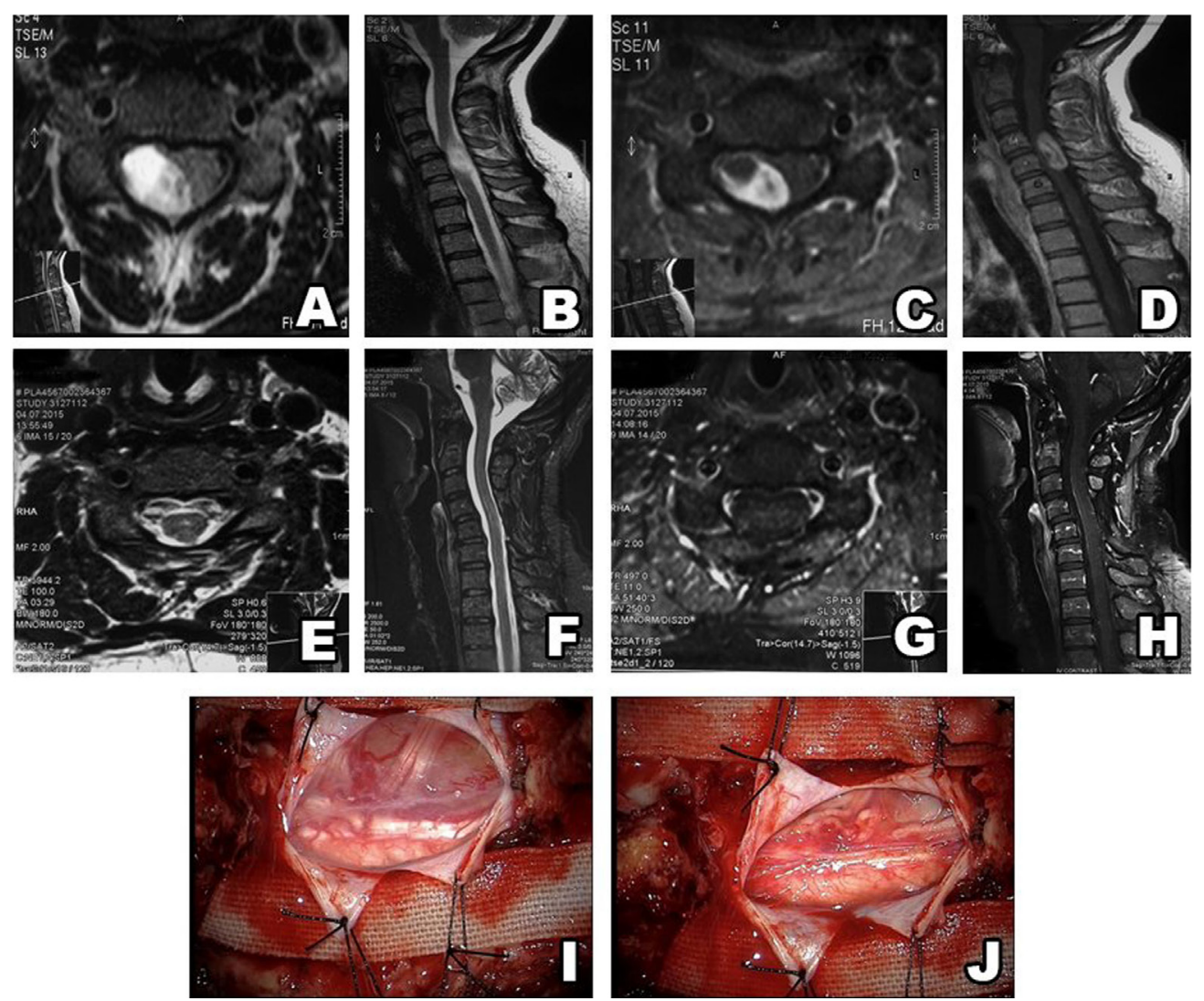

FIGURE 3 | Type II schwannoma (intradural localization). MRI shows a heterogeneous, contrast-enhanced intradural tumor (A-D). Postsurgery MRI confirms gross total resection, without hematoma or recurrence (E-H). A schwannoma inside the dura (I). After resection, there is no residue remaining in surgical field $\mathbf{( J )}$.
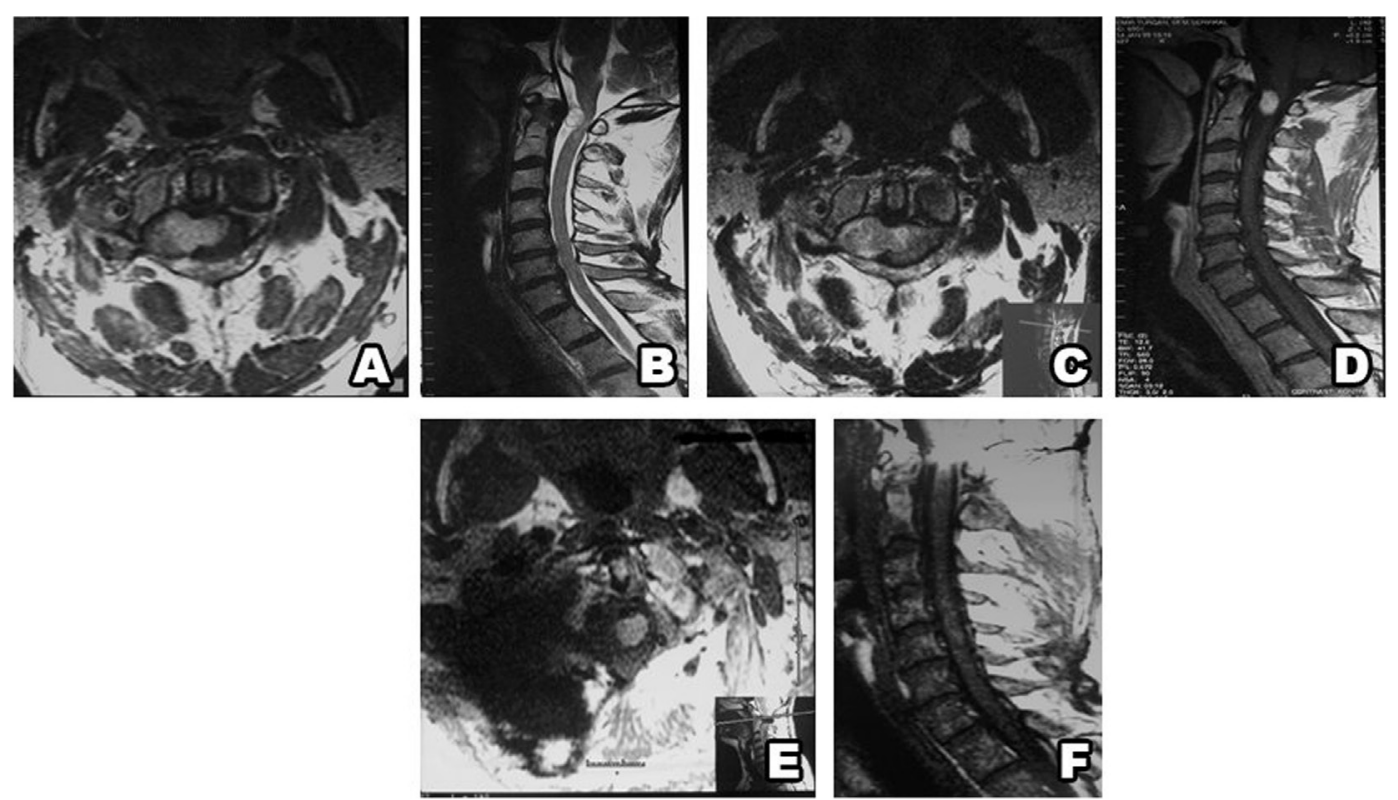

FIGURE 4 | Type II schwannoma (intradural dumbbell-shaped tumor with extension to the extraforaminal region) (A,B), and with contrast enhancement (C,D). Postsurgery MRI confirms gross total resection, without hematoma or recurrence (E,F). 


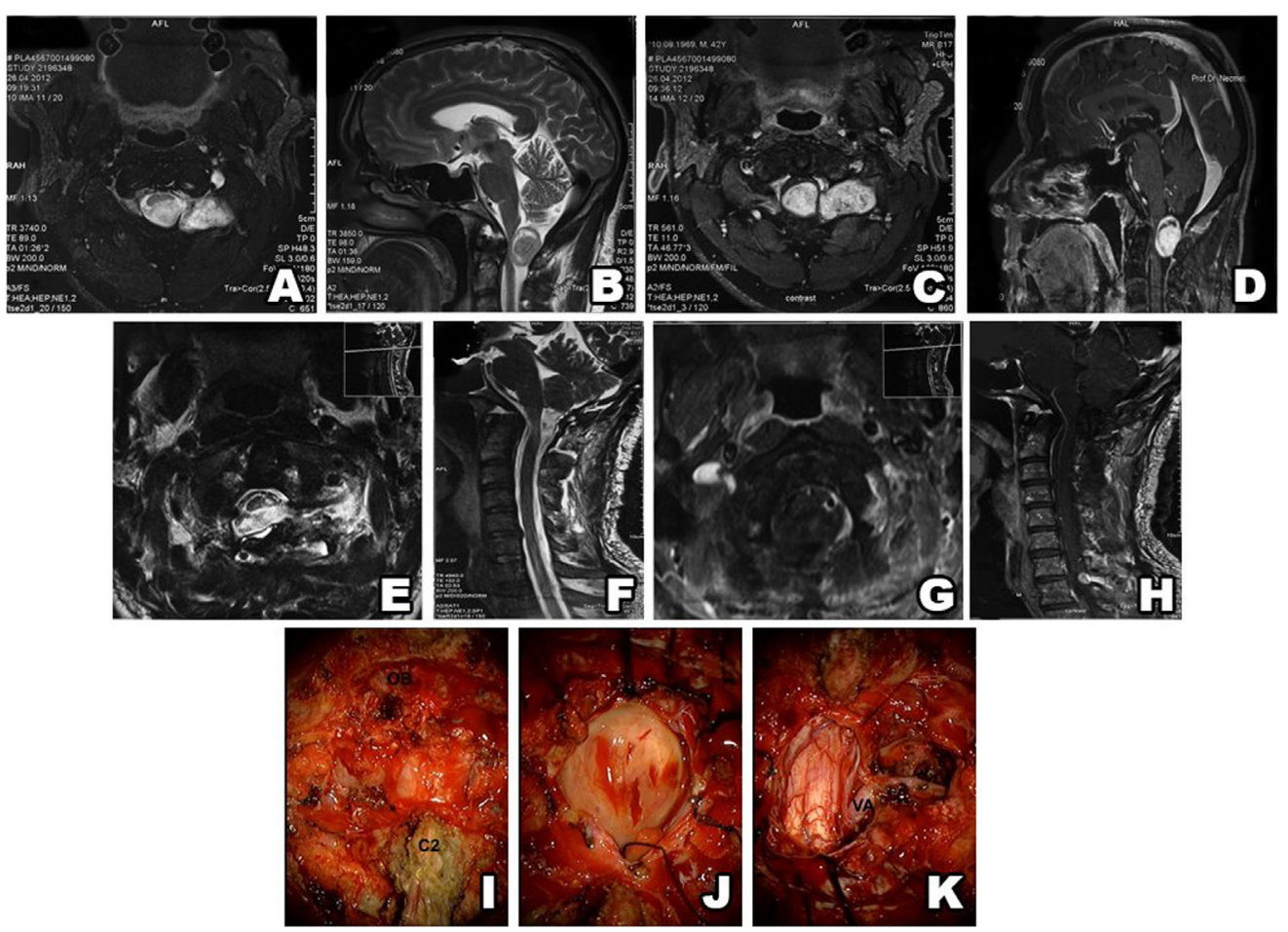

FIGURE 5 | Type III schwannoma (intradural dumbbell-shaped tumor within the spinal canal and extending to the extraforaminal region). Preoperative MRI shows a tumor with extraforaminal extension (A-D). Postsurgery MRI confirms gross total resection, without hematoma or recurrence (E-H). Intraoperative view of a schwannoma extending beyond the spinal canal (I) (OB, occipital bone; C2, second cervical vertebra). Intradural part of a schwannoma (J). Postoperative view of the surgical field shows no tumor residue (K) (VA, vertebral artery).

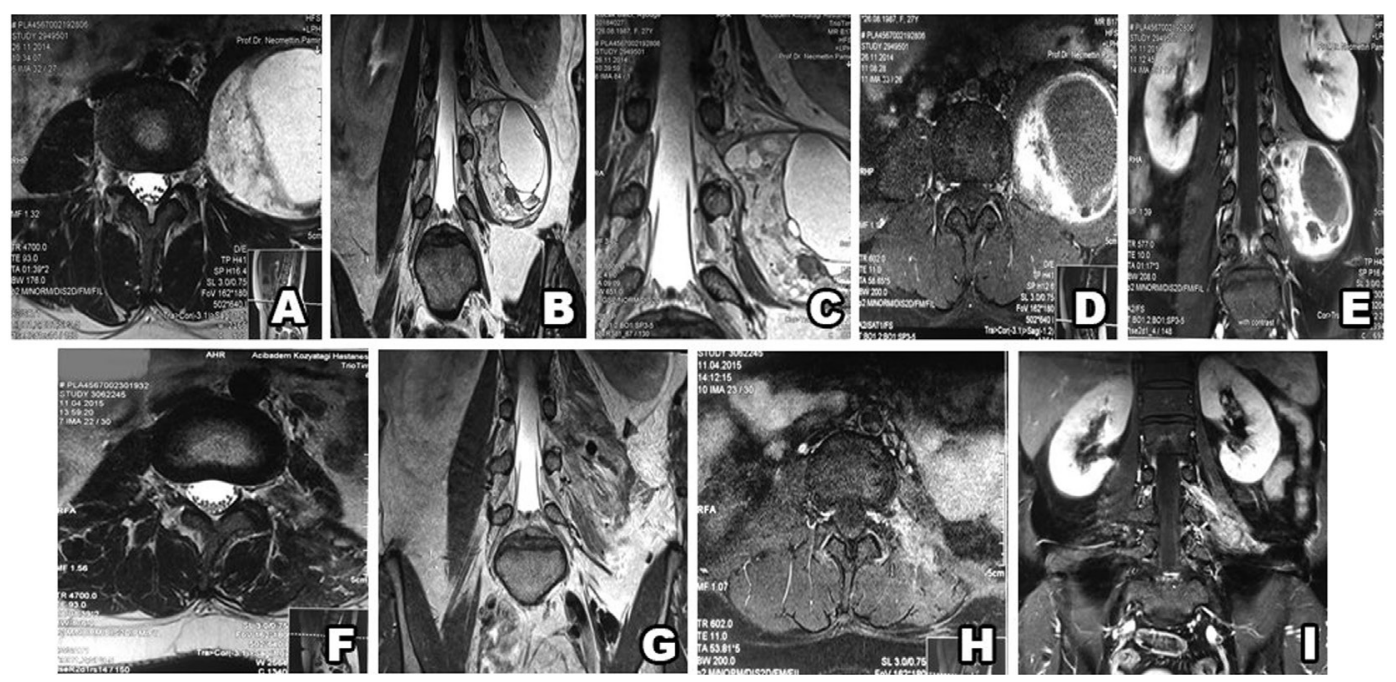

FIGURE 6 | Type IV schwannoma (tumor residing completely outside the root foramina). Preoperative MRI shows a giant cystic schwannoma (A-E), with heterogeneous color enhancement (D,E). Postsurgery MRI confirms gross total resection, without hematoma or recurrence (F-I).

were excluded from the present study. Management of multiple schwannomas is often considerably more complex than that for solitary tumors (4). Retroperitoneally localized schwannomas are rare, comprising approximately $3 \%$ of all schwannomas
(8). Similarly, the present study included just one patient with a retroperitoneal schwannoma. The correlation between tumor volume and MRI findings in the present study shows that type IV tumors were larger than the other types of tumors and that they 


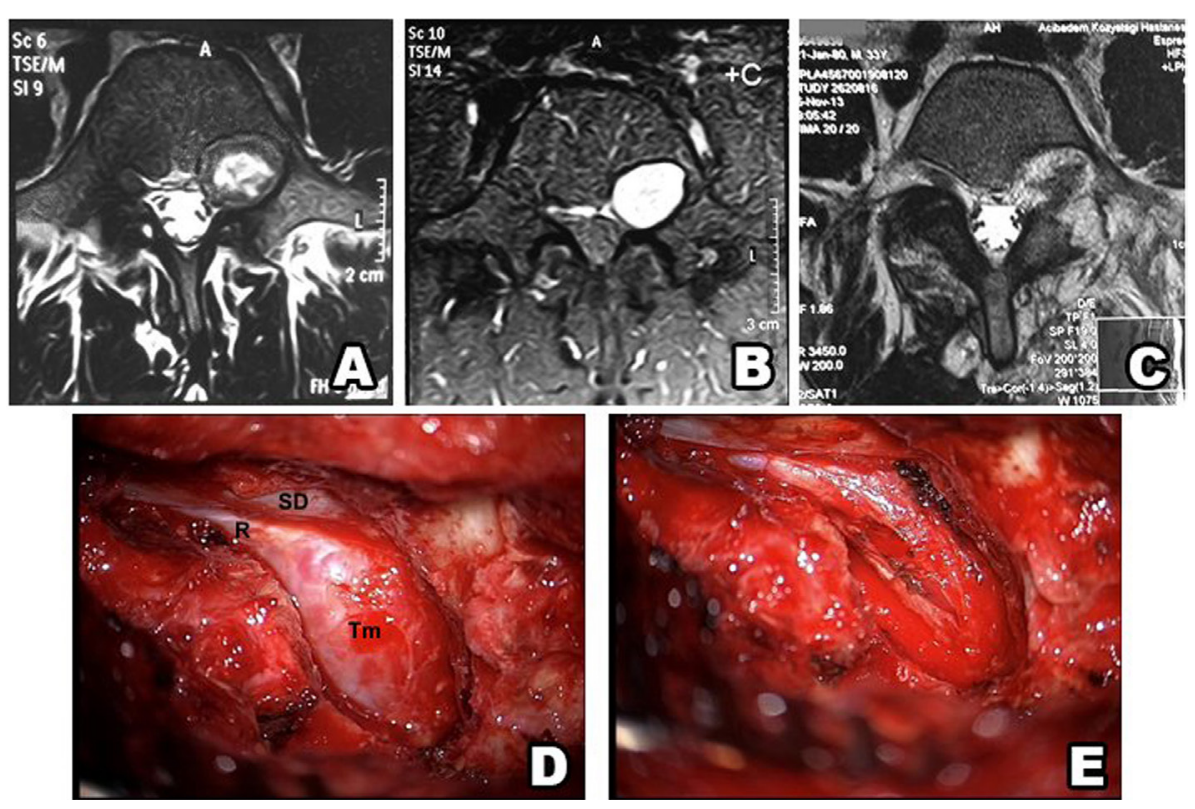

FIGURE 7 | Type IV schwannoma (tumor residing completely outside the root foramina). Preoperative MRI shows a giant cystic spinal schwannoma (A-C). An extraforaminal tumor in the surgical field (D) (SD, spinal dura; R, root; Tm, tumor). Postoperative view of the surgical field shows no tumor residue (E).

did not have margins surrounded by bones, as did intraspinal canal tumors. Intradural tumors become symptomatic sooner than other schwannoma types because they compress the spinal cord. In addition, intradural schwannomas are smaller than the other schwannoma groups in the diagnosis because of this location-dependent pain is a cause to see the physician.

A search of the schwannoma literature was performed for comparison with the present findings. In all, 25 relevant studies published between 1992 and 2016 were found. According to the literature, 2,412 spinal schwannomas cases (including those in the present study) have been reported (Tables 3 and 4). The median of number cases per study was 44, 1,247 (51.69\%) cases were male and $1,165(48.31 \%)$ were female, and mean age was 45.6 years. Tumor localization among the 2,142 cases was as follows: cervical: $33.92 \%$; thoracic: $28.4 \%$; lumbosacral: $37.68 \%$. Data on the extent of surgical resection were available for 2,405 of the cases, and the GTR rate was $93 \%$. Postsurgery functional and neurological scores were reported for 2,138 of the patients; in $79.84 \%$ they increased, in $14.4 \%$ they remained the same, and in $5.76 \%$ they were lower, as compared to presurgery.

The methods used to assess neurological outcome post surgery vary from study to study; as such, comparison is difficult. Nevertheless, the percentage of patients with functional and neurological scores that were lower post surgery might be a reliable measure for evaluating the surgical success rate, as lower functional and neurological scores post surgery are generally due to complications. Studies from 1992 to 2015 reported lower functional and neurological scores post surgery in approximately $5.75 \%$ of patients versus a significantly lower $1.2 \%$ in the present study (which also correlates with the number of patients with complications). As the GTR rate according to meta-analysis was
$93 \%$, reducing the incidence of postoperative side effects is an area to achieve. The novel schwannoma classification system described herein decreased the number of patients with lower functional and neurological scores post surgery by $25 \%$. Establishing and standardizing best practices in the surgical theater is a neverending challenge for all surgery centers. A plethora of factors, ranging from surgeon skill to surgical theater conditions, affect surgical outcome. In addition, presurgery planning is crucial for reducing the incidence of surgical complications. Based on the present findings, we think that the present study's low complication rate is associated with our standardized preoperative planning phase, which is based on our novel schwannoma classification system.

The literature includes numerous schwannoma classification systems. Jinnai and Koyama (2) classified schwannomas into five groups based on the relationship between the tumor and the dura mater and/or intervertebral foramen. This classification system is useful, as it takes into consideration tumor localization relative to the dura, but it does not take into account volume, which is important for preoperative surgical planning. Asazuma et al. (21) devised a schwannoma classification system for cervical dumbbellshaped tumors that consisted of nine categories. An important drawback of their classification system is that it cannot be used for thoracic or lumbar schwannomas, which are as common as cervical schwannomas. Sridhar et al.s (35) classification system is arguably the most similar of the previously reported systems to the novel classification system described herein; however, we think classification of seven distinct types of schwannomas using Sridhar et al.s system is not practical because the characteristics of seven tumors types are difficult to remember. Another drawback of their system is that tumor volume is only considered for 
TABLE 3 | General characteristics of the 25 non-syndromic schwannoma studies published between 1992 and 2015

\begin{tabular}{|c|c|c|c|c|c|c|c|c|c|c|}
\hline Study & Patients (n) & $\begin{array}{c}\text { Male to } \\
\text { female ratio }\end{array}$ & $\begin{array}{l}\text { Mean age } \\
\text { at diagnosis } \\
\text { (years) }\end{array}$ & Cervical (n) & Thoracic (n) & Lumbosacral (n) & $\begin{array}{c}\text { GRT } \\
\text { rate (\%) }\end{array}$ & $\begin{array}{l}\text { Outcome } \\
\text { worse }(n)\end{array}$ & $\begin{array}{l}\text { Outcome } \\
\text { same }(n)\end{array}$ & $\begin{array}{l}\text { Outcome } \\
\text { better }(n)\end{array}$ \\
\hline Friedman et al. (17) & 7 & $3 / 4$ & 46.2 & 1 & 2 & 4 & $\mathrm{~N} / \mathrm{A}$ & $\mathrm{N} / \mathrm{A}$ & $\mathrm{N} / \mathrm{A}$ & $\mathrm{N} / \mathrm{A}$ \\
\hline Seppala et al. (1) & 187 & $83 / 104$ & 48 & 43 & 54 & 90 & 90.1 & 10 & 61 & 116 \\
\hline Asahara et al. (18) & 42 & $17 / 25$ & 45.1 & 12 & 18 & 12 & 97 & $\mathrm{~N} / \mathrm{A}$ & $\mathrm{N} / \mathrm{A}$ & $\mathrm{N} / \mathrm{A}$ \\
\hline McCormick (19) & 12 & $6 / 6$ & 48 & 0 & 6 & 6 & 83.3 & 0 & 0 & 12 \\
\hline Domínguez et al. (20) & 6 & $1 / 5$ & 45 & 0 & 0 & 6 & 83.3 & 0 & 1 & 5 \\
\hline Iwasaki et al. (11) & 4 & $1 / 3$ & 41 & 4 & 0 & 0 & 100 & 0 & 0 & 4 \\
\hline Subaciute (16) & 76 & $25 / 51$ & 47.9 & 19 & 46 & 11 & 98 & 0 & 1 & 75 \\
\hline Asazuma et al. (21) & 42 & $24 / 18$ & 42 & 48 & 0 & 0 & 85.7 & 1 & 11 & 36 \\
\hline Conti et al. (22) & 152 & $59 / 93$ & 44.3 & 33 & 49 & 70 & 95 & 3 & 17 & 132 \\
\hline $\begin{array}{l}\text { Safavi-Abbasi } \\
\text { et al. (3) }\end{array}$ & 128 & $76 / 52$ & 47.7 & 37 & 34 & 57 & 97 & 16 & 0 & 112 \\
\hline Jeon et al. (23) & 38 & $22 / 16$ & 50.2 & 4 & 11 & 25 & 95 & 0 & 3 & 35 \\
\hline Jiang et al. (24) & 44 & 29/15 & 42.3 & 44 & 0 & 0 & 100 & 8 & 0 & 36 \\
\hline $\begin{array}{l}\text { Raysi Dehcordi } \\
\text { et al. (25) }\end{array}$ & 16 & $5 / 11$ & 51 & 16 & 0 & 0 & 100 & 0 & 0 & 16 \\
\hline Fernandes et al. (10) & 30 & $15 / 15$ & 40 & 7 & 10 & 13 & 93.4 & 28 & 1 & 1 \\
\hline Chowdhury et al. (9) & 15 & $8 / 7$ & 35.8 & 15 & 0 & 0 & 100 & 3 & 1 & 11 \\
\hline Altas et al. (26) & 35 & $15 / 20$ & 47.2 & 7 & 10 & 18 & 96 & $\mathrm{~N} / \mathrm{A}$ & $\mathrm{N} / \mathrm{A}$ & $\mathrm{N} / \mathrm{A}$ \\
\hline Yamane et al. (27) & 30 & $18 / 12$ & 48 & 30 & 0 & 0 & 53 & $\mathrm{~N} / \mathrm{A}$ & $\mathrm{N} / \mathrm{A}$ & N/A \\
\hline Deng et al. (28) & 52 & $25 / 27$ & 47.5 & 2 & 23 & 27 & 100 & 0 & 1 & 51 \\
\hline Halvorsen et al. (29) & 131 & $77 / 54$ & 47 & 39 & 23 & 69 & 86 & 16 & 5 & 110 \\
\hline Turel et al. (30) & 164 & $109 / 55$ & 42.6 & 46 & 77 & 44 & 92 & 11 & 39 & 117 \\
\hline Lee et al. (31) & 49 & $25 / 24$ & 45 & 15 & 12 & 22 & 96 & 5 & 0 & 44 \\
\hline Zamorano et al. (32) & 169 & $88 / 81$ & 46.6 & 17 & 48 & 104 & 100 & $\mathrm{~N} / \mathrm{A}$ & $\mathrm{N} / \mathrm{A}$ & N/A \\
\hline Pompili et al. (33) & 70 & $34 / 36$ & 52.2 & 6 & 27 & 37 & 98.6 & 0 & 3 & 67 \\
\hline Li et al. (34) & 831 & $443 / 388$ & 44.8 & 343 & 221 & 267 & 93.9 & 21 & 144 & 666 \\
\hline Pamir & 82 & $39 / 43$ & 45.4 & 34 & 17 & 31 & 98.7 & 1 & 20 & 61 \\
\hline Total & 2,412 & $1,247 / 1,165$ & 45.6 & 822 & 688 & 913 & 93 & 123 & 308 & 1,707 \\
\hline
\end{tabular}

${ }^{*}$ Current research to compare others.

TABLE 4 | The general characteristics of the 2,412 spinal schwannoma cases published between 1992 and 2015 (including the present study).

\begin{tabular}{|c|c|c|}
\hline Schwannoma cases published & 1992 and 201 & \\
\hline Gender & $\mathbf{n}$ & $\%$ \\
\hline Male & 1,247 & 51.69 \\
\hline Female & 1,165 & 48.31 \\
\hline Mean age at diagnosis (years) & & 45.6 \\
\hline Tumor location & Tumors (n) & $\%$ \\
\hline Cervical & 822 & 33.92 \\
\hline Thoracic & 688 & 28.39 \\
\hline Lumbosacral & 913 & 37.68 \\
\hline Gross complete resection & 2,310 & 93.00 \\
\hline Outcome & Patients (n) & $\%$ \\
\hline Better & 1,707 & 79.84 \\
\hline Same & 308 & 14.40 \\
\hline Worse & 123 & 5.75 \\
\hline
\end{tabular}

dumbbell-shaped tumors, and craniocaudal dimension is not a consideration, which limit the diagnostic value and consistency of the classification system. Based on the present findings, we think that all schwannomas should be classified according to localization and volume, so as to achieve the desired benefit of classification-ease and reliability of preoperative decision making and preparation. In addition, our novel spinal schwannoma classification system makes tumor localization easier to understand, as compared to other systems, and is suitable for all schwannoma types.
The present findings help confirm that GTR of non-syndromic spinal schwannomas is safe and effective. Spinal schwannomas should be evaluated via MRI both pre- and postsurgically. Standardized tumor classification prior to any intervention is highly desirable and helpful for surgical planning. Tumor types should be carefully evaluated for optimal surgical planning. The novel spinal schwannoma classification system described herein is a simple and effective tool that the present findings show extremely helpful for avoiding unnecessary surgical approaches and complications. Due to the system's simplicity of having only three tumor groups and its reliability-indicated by the associated low postoperative side effect rate, use of this novel classification system should be considered by any surgical department that seeks a standardized schwannoma surgery protocol.

\section{ETHICS STATEMENT}

This study was carried out in accordance with the recommendations of Acrbadem University Ethical Committee of Medical Research with written informed consent from all subjects. All subjects gave written informed consent in accordance with the Declaration of Helsinki. The protocol was approved by the "Acıbadem University Ethical Committee of Medical Research."

\section{AUTHOR CONTRIBUTIONS}

All authors contributed equally to this work. 


\section{REFERENCES}

1. Seppala MT, Haltia MJ, Sankila RJ, Jaaskelainen JE, Heiskanen O. Long-term outcome after removal of spinal schwannoma: a clinicopathological study of 187 cases. J Neurosurg (1995) 83:621-6. doi:10.3171/jns.1995. 83.4.0621

2. Jinnai T, Koyama T. Clinical characteristics of spinal nerve sheath tumors: analysis of 149 cases. Neurosurgery (2005) 56:510-5. doi:10.1227/01. NEU.0000153752.59565.BB

3. Safavi-Abbasi S, Senoglu M, Theodore N, Workman RK, Gharabaghi A, Feiz-Erfan I, et al. Microsurgical management of spinal schwannomas: evaluation of 128 cases. JNeurosurg Spine (2008) 9:40-7. doi:10.3171/ SPI/2008/9/7/040

4. MacCollin M, Chiocca EA, Evans DG, Friedman JM, Horvitz R, Jaramillo D, et al. Diagnostic criteria for schwannomatosis. Neurology (2005) 64:1838-45. doi:10.1212/01.WNL.0000163982.78900.AD

5. Gottfried ON, Binning MJ, Schmidt MH. Surgical approaches to spinal schwannomas. Contemp Neurosurg (2005) 27:1-9. doi:10.1097/00029679200502280-00001

6. Javalkar VK, Pigott T, Pal P, Findlay G. Multiple schwannomas: report of two cases. Eur Spine J (2007) 16:287-92. doi:10.1007/s00586-006-0303-9

7. Yu NH, Lee SE, Jahng TA, Chung CK. Giant invasive spinal schwannoma: its clinical features and surgical management. Neurosurgery (2012) 71:58-66. doi:10.1227/NEU.0b013e31824f4f96

8. Cury J, Coelho RF, Srougi M. Retroperitoneal schwannoma: case series and literature review. Clinics (2007) 62:359-62. doi:10.1590/S180759322007000300024

9. Chowdhury FH, Haque MR, Sarker MH. High cervical spinal schwannoma; microneurosurgical management: an experience of 15 cases. Acta Neurol Taiwan (2013) 22:59-66.

10. Fernandes RL, Lynch JC, Welling L, Gonçalevs M, Tragante R, Temponi V, et al. Complete removal of the spinal nerve sheath tumors. Surgical techniques and results from a series of 30 patients. Arq Neuropsiquiatr (2014) 72:312-7. doi:10.1590/0004-282X20140008

11. Iwasaki Y, Hida K, Koyanagi I, Yoshimoto T, Abe H. Anterior approach for dumbbell type cervical neurinoma. Neurol Med Chir (1999) 39:835-9. doi: $10.2176 /$ nmc.39.835

12. Kim P, Ebersold MJ, Onofrio BM, Quast LM. Surgery of spinal nerve schwannoma. Risk of neurological deficit after resection of involved root. J Neurosurg (1989) 71:810-4. doi:10.3171/jns.1989.71.6.0810

13. Klekamp J, Samii M. Introduction of a score system for the clinical evaluation of patients with spinal processes. Acta Neurochir (1993) 123:221-3.

14. Seppala MT, Haltia MJ. Spinal malignant nerve-sheath tumor or cellular schwannoma? A striking difference in prognosis. JNeurosurg (1993) 79: 528-32. doi:10.3171/jns.1993.79.4.0528

15. Parmar H, Patkar D, Gadani S, Shah J. Cystic lumbar nerve sheath tumours: MRI features in five patients. Australas Radiol (2001) 45:123-7. doi:10.1046/ j.1440-1673.2001.00891.x

16. Subaciute J. [Early diagnosis of spinal cord schwannoma: the significance of the pain syndrome]. Medicina (2002) 38:1086-8.

17. Friedman DP, Tartaglino LM, Flanders AE. Intradural schwannomas of the spine: MR findings with emphasis on contrast-enhancement characteristics. AJR Am J Roentgenol (1992) 158(6):1347-50. doi:10.2214/ajr.158.6. 1590138

18. Asahara H, Kawai A, Harada Y, Senda M, Inoue H. Spinal schwannomas: a review of 42 cases. Acta Med Okayama (1996) 50:25-8.

19. McCormick PC. Surgical management of dumbbell tumors of the cervical spine. Neurosurgery (1996) 38(2):294-300. doi:10.1097/00006123-19960200000012

20. Domínguez J, Lobato RD, Ramos A, Rivas JJ, Gómez PA, Castro S. Giant intrasacral schwannomas: report of six cases. Acta Neurochir (1997) 139(10): 954-60. doi:10.1007/BF01411305

21. Asazuma T, Toyama Y, Maruiwa H, Fujimura Y, Hirabayashi K. Surgical strategy for cervical dumbbell tumors based on a three-dimensional classification. Spine (2004) 29:E10-4. doi:10.1097/01.BRS.0000103662. 13689.76

22. Conti P, Pansini G, Mouchaty H, Capuano C, Conti R. Spinal neurinomas: retrospective analysis and long-term outcome of 179 consecutively operated cases and review of the literature. Surg Neurol (2004) 61(1):34-43. doi:10.1016/ S0090-3019(03)00537-8

23. Jeon JH, Hwang HS, Jeong JH, Park SH, Moon JG, Kim CH. Spinal schwannoma; analysis of 40 cases. J Korean Neurosurg Soc (2008) 43(3):135-8. doi:10.3340/jkns.2008.43.3.135

24. Jiang L, Lv Y, Liu XG, Ma QJ, Wei F, Dang GT, et al. Results of surgical treatment of cervical dumbbell tumors: surgical approach and development of an anatomic classification system. Spine (2009) 34(12):1307-14. doi:10.1097/ BRS.0b013e3181a27a32

25. Raysi Dehcordi S, Marzi S, Ricci A, Di Cola F, Galzio RJ. Less invasive approaches for the treatment of cervical schwannomas: our experience. Eur Spine J (2012) 21(5):887-96. doi:10.1007/s00586-011-2118-6

26. Altaş M, Cerçi A, Silav G, Sari R, Coşkun K, Balak N, et al. Microsurgical management of non-neurofibromatosis spinal schwannoma. Neurocirugia (2013) 24(6):244-9. doi:10.1016/j.neucir.2012.01.002

27. Yamane K, Takigawa T, Tanaka M, Osaki S, Sugimoto Y, Ozaki T. Factors predicting clinical impairment after surgery for cervical spinal schwannoma. Acta Med Okayama (2013) 67(6):343-9.

28. Deng Q, Tian Z, Sheng W, Guo H, Dan ME. Surgical methods and efficacies for cervicothoracolumbar spinal schwannoma. Exp Ther Med (2015) 10(6):2023-8. doi:10.3892/etm.2015.2803

29. Halvorsen CM, Rønning P, Hald J, Johannesen TB, Kolstad F, Langmoen IA, et al. The long-term outcome after resection of intraspinal nerve sheath tumors: report of 131 consecutive cases. Neurosurgery (2015) 77(4):585-93. doi:10.1227/NEU.0000000000000890

30. Turel MK, D'Souza WP, Rajshekhar V. Hemilaminectomy approach for intradural extramedullary spinal tumors: an analysis of 164 patients. Neurosurg Focus (2015) 39(2):E9. doi:10.3171/2015.5.FOCUS15170

31. Lee SE, Jahng T-A, Kim HJ. Different surgical approaches for spinal schwannoma: a single surgeon's experience with 49 consecutive cases. World Neurosurg (2015) 84(6):1894-902. doi:10.1016/j.wneu.2015.08.027

32. Zamorano J, Fehlings M, Nater A, Tetrault L, Varga P, Gokaslan Z, et al. Risk factors for local recurrence after surgical resection of spine schwannomas: retrospective analysis of 169 patients from a multicenter international database. Global Spine J (2015) 5(1_suppl):s-0035. doi:10.1055/s-00351554109

33. Pompili A, Caroli F, Crispo F, Giovannetti M, Raus L, Vidiri A, et al. Unilateral laminectomy approach for the removal of spinal meningiomas and schwannomas: impact on pain, spinal stability, and neurologic results. World Neurosurg (2016) 85:282-91. doi:10.1016/j.wneu.2015.09.099

34. Li P, Zhao F, Zhang J, Wang Z, Wang X, Wang B, et al. Clinical features of spinal schwannomas in 65 patients with schwannomatosis compared with 831 with solitary schwannomas and 102 with neurofibromatosis type 2: a retrospective study at a single institution. J Neurosurg Spine (2016) 24(1):145-54. doi:10.3171/2015.3.SPINE141145

35. Sridhar K, Ramamurthi R, Vasudevan MC, Ramamurthi B. Giant invasive spinal schwannomas: definition and surgical management. J Neurosurg (2001) 94:210-5.

Conflict of Interest Statement: The authors declare that the research was conducted in the absence of any commercial or financial relationships that could be construed as a potential conflict of interest.

Copyright (c) 2017 Sun and Pamir. This is an open-access article distributed under the terms of the Creative Commons Attribution License (CC BY). The use, distribution or reproduction in other forums is permitted, provided the original author(s) or licensor are credited and that the original publication in this journal is cited, in accordance with accepted academic practice. No use, distribution or reproduction is permitted which does not comply with these terms. 